\title{
Data Analytics for Concrete Structural Health Monitoring in Nuclear Power Plants
}

\section{European Safety and Reliability Conference}

\author{
V. Agarwal and B. P. Hallbert \\ (Idaho National Laboratory) \\ Y. Bao, S. Mahadevan, D. Adams \\ (Vanderbilt University)
}

September 2015

The INL is a

U.S. Department of Energy

National Laboratory

operated by

Battelle Energy Alliance

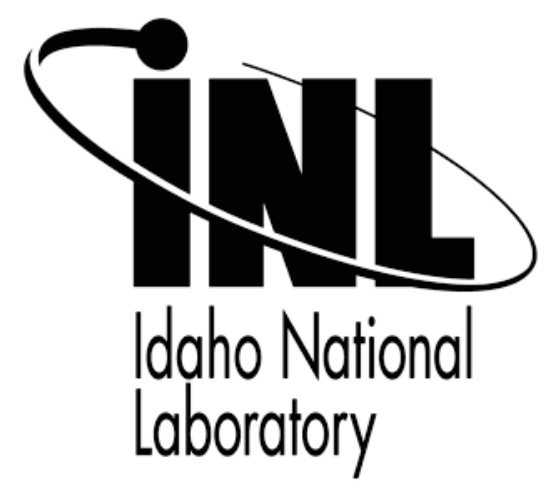

This is a preprint of a paper intended for publication in a journal or proceedings. Since changes may be made before publication, this preprint should not be cited or reproduced without permission of the author. This document was prepared as an account of work sponsored by an agency of the United States Government. Neither the United States Government nor any agency thereof, or any of their employees, makes any warranty, expressed or implied, or assumes any legal liability or responsibility for any third party's use, or the results of such use, of any information, apparatus, product or process disclosed in this report, or represents that its use by such third party would not infringe privately owned rights. The views expressed in this paper are not necessarily those of the United States Government or the sponsoring agency. 



\title{
Data Analytics for Concrete Structural Health Monitoring in Nuclear Power Plants
}

\author{
V. Agarwal \\ Department of Human Factors, Controls, and Statistics, Idaho National Laboratory, Idaho Falls, ID, USA
}

Y. Bao, S. Mahadevan, \& D. Adams

Department of Civil and Environmental Engineering, Vanderbilt University, Nashville, TN, USA

B. P. Hallbert

Nuclear Science and Technology Directorate, Idaho National Laboratory, Idaho Falls, ID, USA

\begin{abstract}
Assessment and management of aging concrete structures in nuclear power plants require a more systematic approach than simple reliance on existing code margins of safety. Structural health monitoring of concrete structures aims to understand the current health condition of a structure based on heterogeneous measurements to produce high-confidence actionable information regarding structural integrity that supports operational and maintenance decisions. This ongoing research project is seeking to develop a probabilistic framework for health diagnosis and prognosis of aging concrete structures in a nuclear power plant that is subjected to physical, chemical, and mechanical degradation. In this paper, the experimental set-up at Vanderbilt University's Laboratory for Systems Integrity and Reliability was used to research effective combinations of full-field imaging techniques, which include infrared thermography, digital image correlation, and ultrasonic measurement. The full-field imaging data collected were processed using contour mapping techniques to identify holes in a concrete slab. The techniques discussed and presented in this paper allow diagnosis of damage. The framework will enable plant operators to make risk-informed decisions on the structural integrity, remaining useful life, and performance of concrete structures.
\end{abstract}

\section{INTRODUCTION}

One of the challenges for the current fleet of light water reactors (LWRs) in the United States is agerelated degradation of their passive assets that include concrete, cables, piping, and reactor pressure vessel. As the current fleet of nuclear power plants (NPPs) continue to operate up to 60 years or beyond, it is important to understand the current and the future health condition of passive assets under different operating conditions that would support operational and maintenance decisions. To ensure longterm safe and reliable operation of the current fleet, the U.S. Department of Energy's Office of Nuclear Energy funds the Light Water Reactor Sustainability (LWRS) Program to develop the scientific basis for extending the operation of commercial LWRs beyond the current license extension period.

Reinforced concrete structures found in NPPs can be grouped into four categories: primary containment, containment internal structures, secondary containments/reactor buildings, and spent fuel pool and cooling towers (Naus 2007). These concrete structures are affected by a variety of degradation mechanisms related to chemical, physical, and mechanical causes, and irradiation. The age-related degradation of concrete results in gradual microstructural changes (slow hydration, crystallization of amorphous constituents, reactions between cement paste and aggregates, etc.). Changes over long periods of time must be measured, monitored, and analyzed to best support long-term operation and maintenance decisions.

Structural health monitoring (SHM) of concrete structures aims to understand the current health condition of a structure based on heterogeneous measurements to produce high-confidence actionable information regarding structural integrity and reliability.

To achieve this research objective, Vanderbilt University, in collaboration with Idaho National Laboratory (INL) and Oak Ridge National Laboratory (ORNL) has proposed a probabilistic framework of research activities for the health monitoring of NPP concrete structures subject to physical, chemical, and mechanical degradation. A systematic approach proposed to assess and manage aging concrete structures requires an integrated framework.

The methodologies described in this paper are focused on concrete SHM measurements and data analytics to diagnose damage in a concrete sample that will support continuous assessment of concrete performance. This research is in its early stages and would be enhanced in coming years to evaluate fullfield imaging techniques on reinforced concrete 
structures found in NPPs with chemical degradation like alkali-silica reactions.

\section{CONCRETE STRUCTURES HEALTH MONITORING FRAMEWORK}

This ongoing research is based on the framework shown in Figure 1. The framework will investigate health diagnosis and prognosis of aging concrete structures in NPPs subjected to physical, chemical, and mechanical degradation (Agarwal \& Mahadevan 2014) by integrating four elements: (1) damage modeling, (2) monitoring, (3) data analytics, and (4) uncertainty quantification. The framework will enable plant operators to make risk-informed decisions on the structural integrity, remaining useful life, and performance of concrete structures. Each element of the framework is briefly explained below.

\subsection{Damage modeling}

This element leverages the modeling of chemical, physical, and mechanical degradation mechanisms (such as alkali-aggregate reaction, chloride penetration, sulfate attack, carbonation, freeze-thaw cycles, shrinkage, and radiation damage) to assist monitoring and risk management decisions. Alkali-aggregate reaction is currently receiving prominent attention; however, other appropriate damage mechanisms for NPP concrete structures can also be included. The interactions of multiple mechanisms need significant consideration.

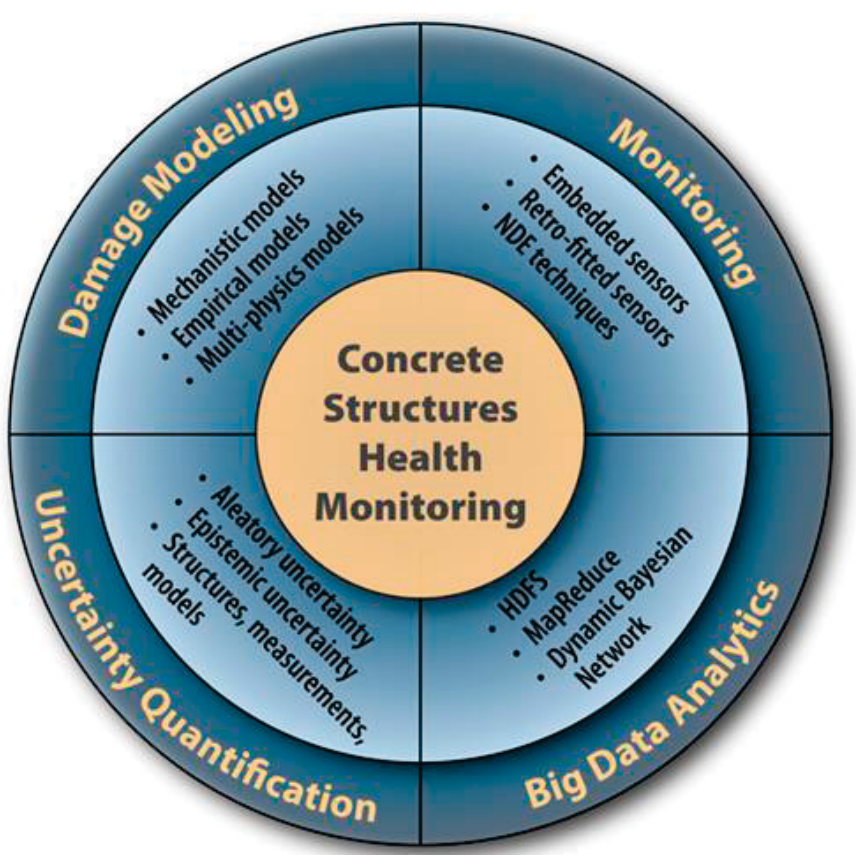

Figure 1. Elements of concrete structures health monitoring (Agarwal \& Mahadevan, 2014).
The task requires modeling and computational advances and combined-physics experiments, and the integration of multiple models through an appropriate simulation framework.

\subsection{Monitoring}

This element explores effective combination of promising SHM techniques for full-field multi-physics monitoring of concrete structures. Optical, thermal, acoustic, and radiation-based techniques will be investigated for full-field imaging. Examples of these techniques include digital image correlation (DIC), infrared imaging, velocimetry and ultrasonic, and X-ray tomography. A particular consideration is the linkage of chemical degradation mechanisms to the observed degradation, which requires synergy between the damage modeling and monitoring research.

\subsection{Data analytics}

The information gathered from multiple health monitoring techniques results in high volume, rate, and variety (heterogeneity) of data. This element leverages big data techniques to store, process, and analyze heterogeneous data (numerical, text and image) and arrives at effective inference of concrete degradation. The data analytics framework can also integrate information from model prediction, laboratory experiments, plant experience and inspections, and expert opinion. Data mining, classification and clustering, feature extraction and selection, and fault signature analyses with heterogeneous data can be orchestrated through a Bayesian network for effective inference.

\subsection{Data analytics}

This element will quantify the uncertainty in health diagnosis and prognosis in a manner that facilitates risk-management decisions. Sources of natural variability, data uncertainty, and model uncertainty arising in both modeling and monitoring activities can be considered and their effects quantified. In addition to measurement and processing errors, data uncertainty due to sparse and imprecise data for some quantities, and due to large data on other quantities (data quality, relevance, scrubbing) can be considered. Model uncertainty in multi-physics degradation modeling due to model form, model parameters, and solution approximations can be included. The various uncertainty sources do not combine in a simple manner; therefore, a systematic Bayesian network approach should be developed for comprehensive uncertainty quantification in a manner that is informative to the decision-maker for operation, maintenance, inspection, and other risk-management activities. 


\section{MONITORING}

Based on the initial review of literature, presentations, and discussions on current activities related to concrete structures deterioration modeling and monitoring at the workshop (Mahadevan et al. 2014), this research will investigate monitoring of physical chemical mechanical coupled degradation in concrete via full-field imaging techniques (thermal, optical, and acoustic). Effective combinations of fullfield techniques need to be identified for different types of concrete structures under different loading and operating conditions. In this paper, possible fullfield techniques include infrared imaging, DIC, and ultrasonic.

Infrared thermography maps the thermal load path in a material. In the case of concrete, cracking, spalling, and delamination all create a discontinuity in the thermal load path. Kobayashi \& Banthia (2011) combined induction heating with infrared thermography to detect corrosion in reinforced concrete.

Digital Image Correlation is an optical non-destructive examination (NDE) technique. It can be conducted quickly, which allows it to be used as a screening method. DIC is capable of measuring deformation, displacement, and strain of a structure (Bruck 2012). DIC is capable of detecting surface defects such as cracks, micro-cracks, and spalling, but is unable to detect any subsurface defects.

Ultrasonic testing utilizes high-frequency oscillating sound pressure waves. In a recent study led by ORNL, five NDE techniques were evaluated, including shear-wave ultrasound and semi-coupled ultrasonic tomography. The shear-wave ultrasound consisted of a $4 \times 12$ array that was capable of producing real time three-dimensional imaging. The semi-coupled ultrasonic tomography was excellent at identifying internal void areas and unbounded, embedded rebar. Both techniques did show some limitations; the semi-coupled ultrasonic tomography was unable to detect well-bonded rebar, and the shear-wave ultrasound is in need of post-processing of the data (Clayton 2014).

\subsection{Concrete Slab}

The full-field imaging techniques are applied to a commercially available small concrete slab with the dimensions of $15.5 \times 15.5 \times 1.75$ inches. No information about its fabrication is available and is presumed to have no physical, chemical, or mechanical damage to begin with. The concrete slabs were intially constrained (with a steel frame) and later unconstrained. The purpose of constraining the sample was to increase the stresses and be able to detect them using the full-field imaging techniques. Heat was applied to the bottom of the concrete slab using a silicone thermal blanket as per the temperature profile, shown in Figure 2, to induce strains in the slab due to thermal expansion. To reduce heat loss in the concrete sample from the convection and conduction effects between the thermal blanket and the steel frame, insulation sheets were installed.

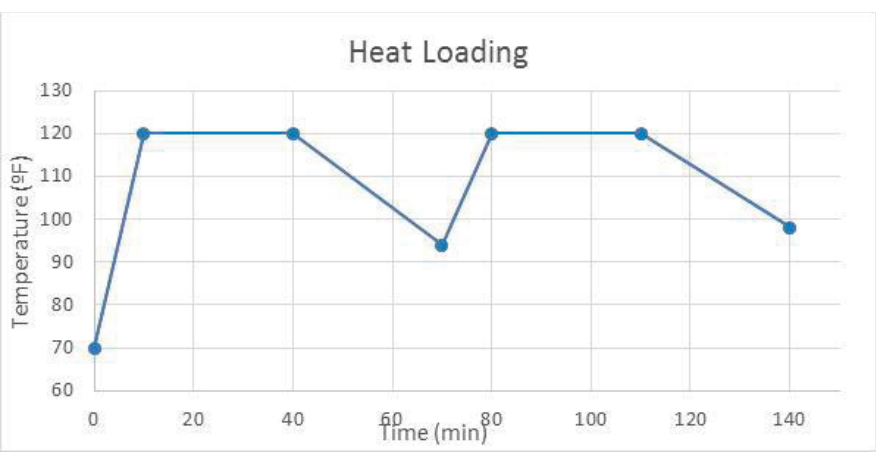

Figure 2. Temperature profile applied to the concrete slab.

The initial temperature of the slab and equipment was $70^{\circ} \mathrm{F}$, which is the ambient temperature in the Laboratory for Systems Integrity and Reliability (LASIR). Each thermal cycle had a total duration of 70 minutes. During the first 10 minutes of the first thermal cycle, the blanket temperature increased to $120^{\circ} \mathrm{F}$. The temperature was held at $120^{\circ} \mathrm{F}$ for 30 minutes and then for the next 30 minutes the HEATCON $^{\circledR}$ unit was turned off to allow the temperature to drop to $95^{\circ} \mathrm{F}$. The second cycle was similar to the first cycle, but the positive slope differed from the first cycle. The positive slope for the first cycle was $5^{\circ} \mathrm{F} / \mathrm{min}$ and for the second cycle was $3^{\circ} \mathrm{F} / \mathrm{min}$.

Holes of 1/2-inch, 3/8-inch, and 5/16-inch diameters at a depth of 4.45 inch were drilled into the side of the concrete slab, as shown in Figure 3. The holes are presumed to represent damage present in the concrete slab. The concrete slab with holes was subjected to a thermal loading cycle (as in Figure 2).

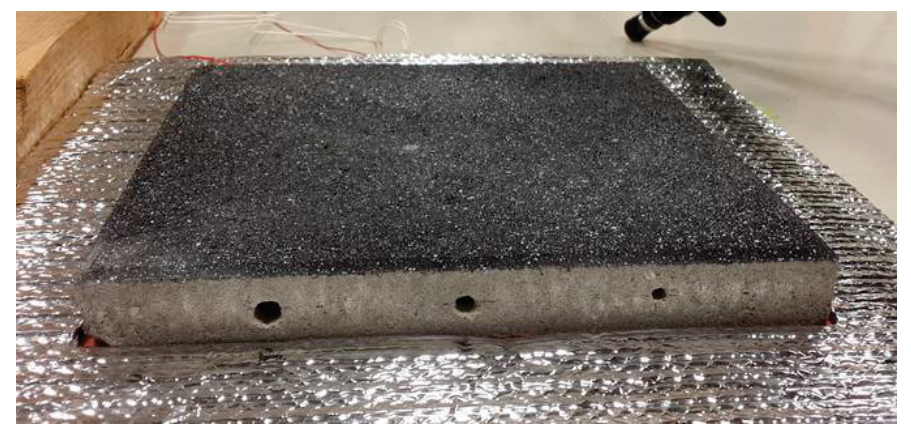

Figure 3. Image of the concrete slab with the dimensions of $15.5 \times 15.5 \times 1.75$ inches with holes. 


\subsection{Laboratory Step-Up}

An experimental set-up, as shown in Figure 4, was built in the LASIR at Vanderbilt University to assess the behavior of stressed concrete slabs with and without holes when subjected to thermal loading using the three monitoring or NDE techniques.

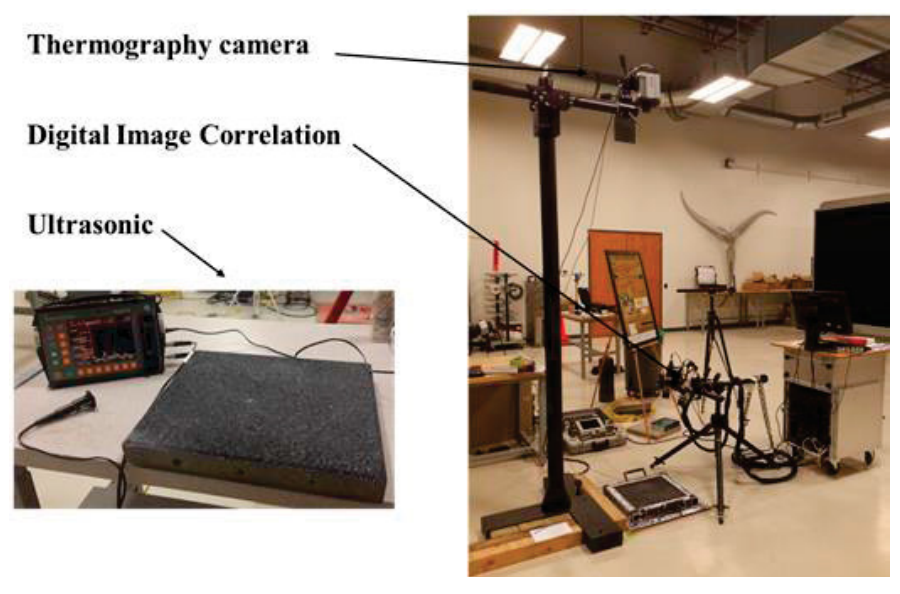

Figure 4. An experimental set-up in the LASIR at Vanderbilt University. (Left) Concrete slab with holes along with the ultrasonic measurement unit. (Right) Concrete slab with thermography imaging and DIC measuring units.

For thermography imaging, a FLIR ${ }^{\circledR}$ Infrared (IR) camera was used to detect the temperature contours on the surface of the concrete slab. These contours were analyzed to detect flaws or defects in the slabs that cannot be easily detected by visual inspection. For DIC, two high-speed video cameras to track the motion of speckles painted onto the surface of the slab were utilized. The speckles are produced due to strain and deformation of the concrete slab during the duration of the cyclic thermal loading. Both FLIR $^{\circledR}$ IR camera and DIC were set up to capture images of the concrete slab every 2 minutes. For ultrasonic inspection, a General Electric Phased array unit was used to detect the damage in the slab by sending out a signal and measuring the time of flight of the transmitted signal when it reflects from each surface in the material (for example, cracks, holes, or large aggregate). The density of the material is used along with a 5-MHz ultrasonic probe to detect the location and depth of holes and cracks in the concrete samples.

In addition, the HEATCON ${ }^{\circledR}$ composite system controller was connected to the thermal blanket and used to program a defined thermal cycle that can be repeated as many times as needed for a test. Two thermocouples were used to measure and monitor the heat applied by the thermal blanket. One thermocouple was placed beneath the blanket and the other thermocouple was place between the thermal blanket and the concrete sample.

\subsection{Ultrasonic Measurements}

Ultrasonic testing was only conducted on the test samples with holes drilled since the goal is to detect the location and depth of the holes. Figure 5 shows the locations where the ultrasonic probe was placed to run the test. Ultrasonic signals were collected at each location and Table 1 summarizes the distance from the surface to the holes, calculated using unprocessed data.

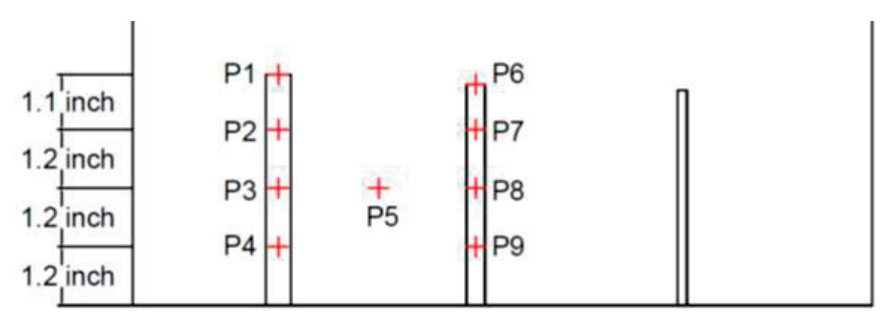

Figure 5. Locations where ultrasonic probes were placed.

Table 1. Ultrasonic measurement of the holes' depth.

\begin{tabular}{ll}
\hline Probe Location & Distance from the surface to the hole \\
$(\mathrm{cm})$
\end{tabular}

\subsection{Thermography Imaging}

By using the images that were measured using the thermography camera, the holes drilled in the slab and the depth of the holes were identified. Temperature contours on the surface of the slab were also analyzed to detect flaws or defects that cannot be easily detected by visual inspection. Contour images were captured every 2 minutes.

Figure 6 shows thermographic images of the slab without and with holes measured at 24 minutes from the beginning of the thermal cycle. The locations of the holes are visually apparent by comparing the images of the slab without and with holes. Because of

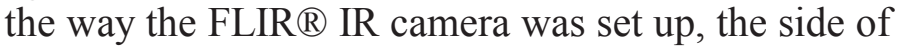
the slab with holes is located at the right side of the image. Note that these results were derived from raw data and further processing would likely lead to higher fidelity results. 


\section{Without Holes}

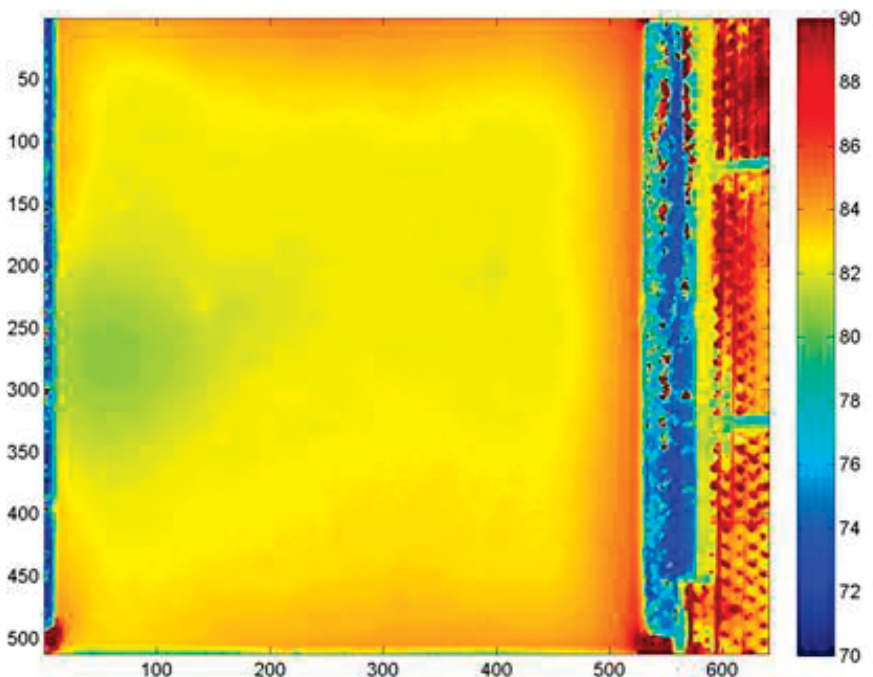

(a)

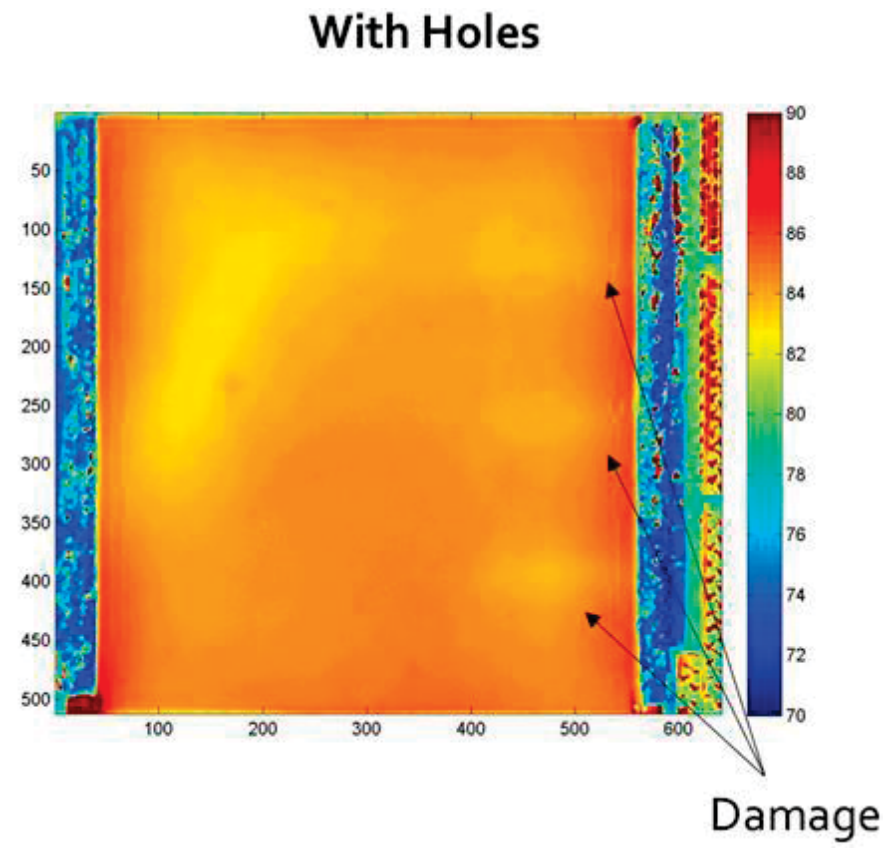

(b)

Figure 6. Thermographic images of the slab (a) without holes and (b) with holes at 24 minutes into the thermal cycle.

\subsection{Digital Image Correlation}

DIC was used to obtain strain data. Figure 7 shows strain images of the slab without and with holes, measured at 110 minutes of the thermal cycle. Because of the way in which the equipment was set up, the holes are located on the left side of the slab in the strain images, as indicated in Figure 7. The larger holes are located in the upper half of the slab. The results verify that the strain values at the location where the large holes were located are significantly higher than in the rest of the slab. Also, the strain is largest at the edge of the slab where the two largest holes are located compared to the strain in the slab without holes.

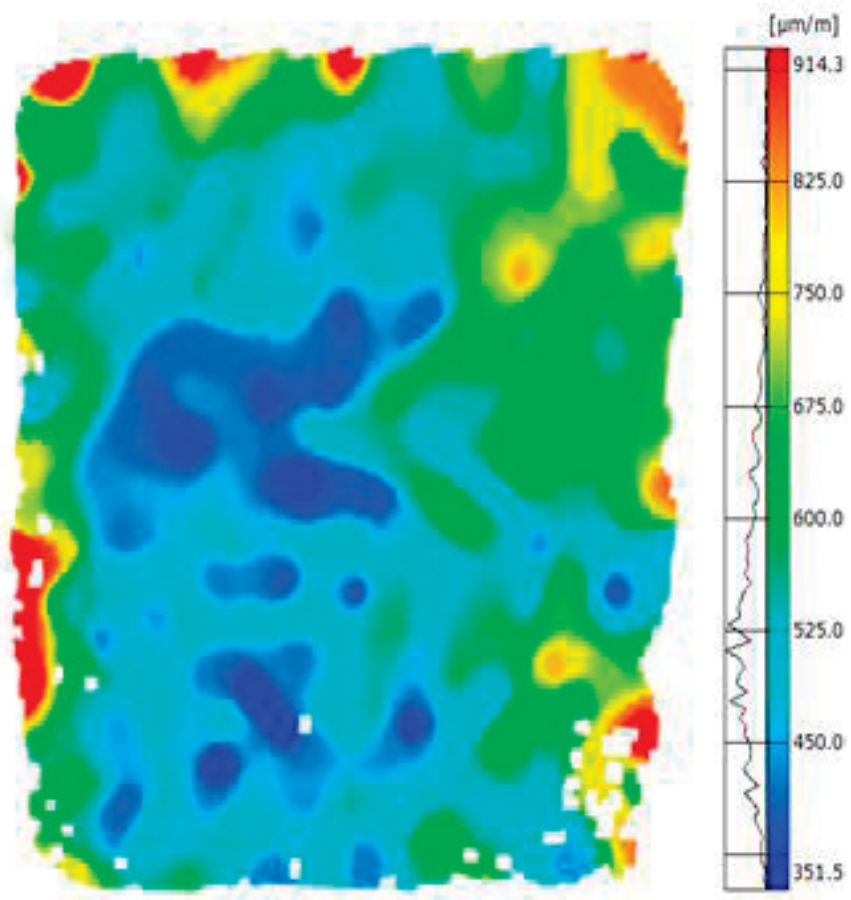

(a)

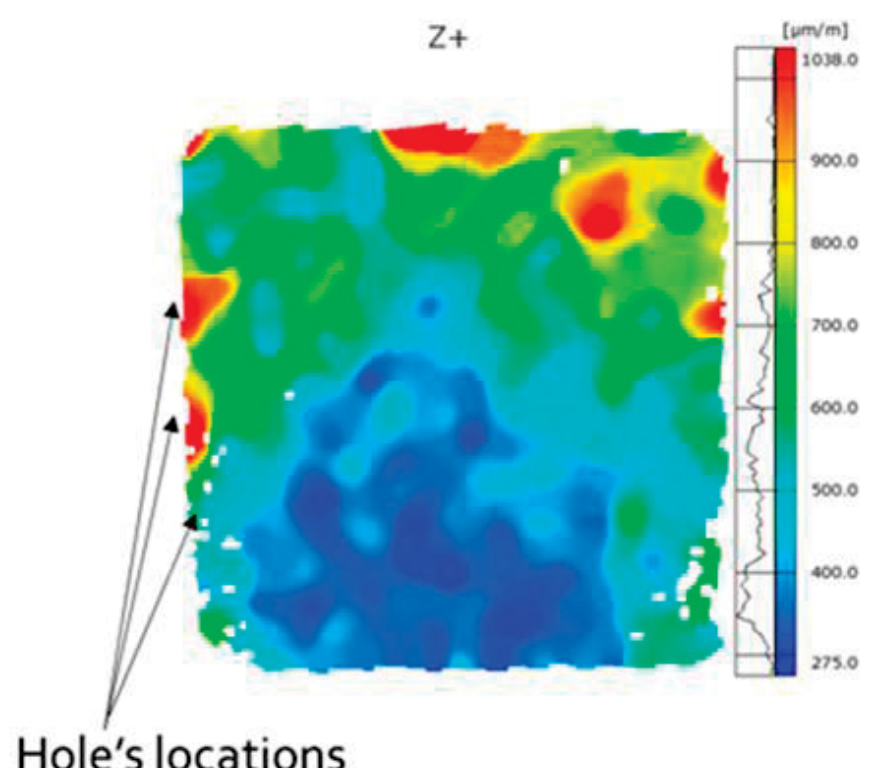

(b)

Figure 7. Strain images of the slab $(\mathrm{Z}+$ direction [i.e., upward direction perpendicular to the slab]) without holes (a) and with holes (b) measured at 110 minutes of the thermal cycle.

\section{DATA ANALYTICS}

The full-field imaging data are processed and analyzed to generate contour maps. Due to operational and experimental imperfection, the image captured has a significant level of noise. Therefore, smoothing is an important step in post processing. Smoothing of the information set is done to make an approxima- 
tion that endeavors to catch the essential information, while ignoring noise (or other fine-scale structures) and transient phenomena.

\subsection{Contour Mapping}

Contour lines depict the crossing point of a genuine or speculative surface with one or more level planes. The configuration of these contours permits us to deduce relative inclination of a parameter and appraisal of that parameter at particular spots. In this research, contours could assist in approximately identifying the damaged zone. It is extremely useful for feature extraction. Figures 8 and 9 show temperature contours in the slab after 20 minutes of thermal loading, without and with holes. The holes are visually observable in the second image in Figure 9.

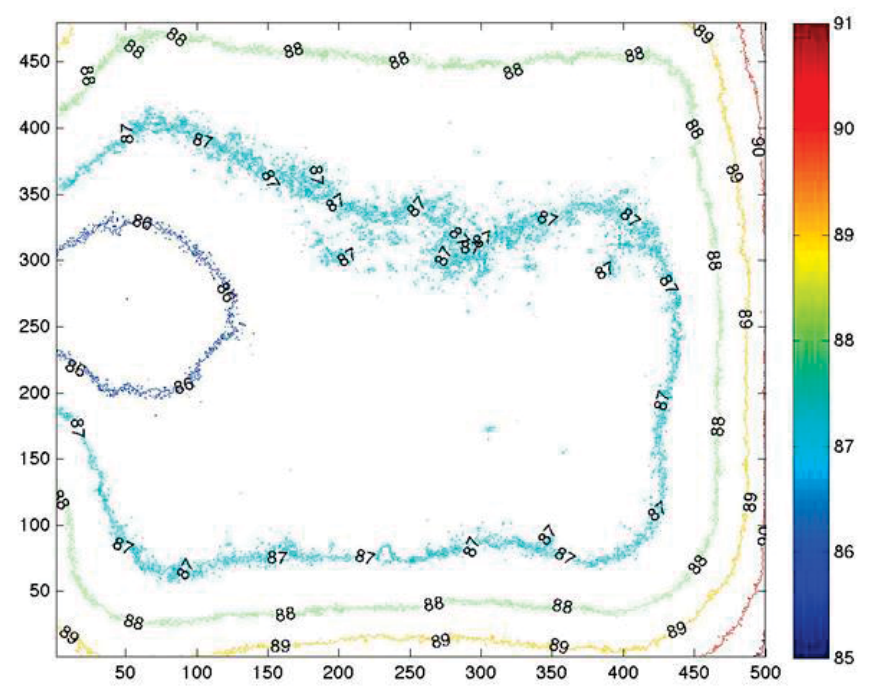

(a)

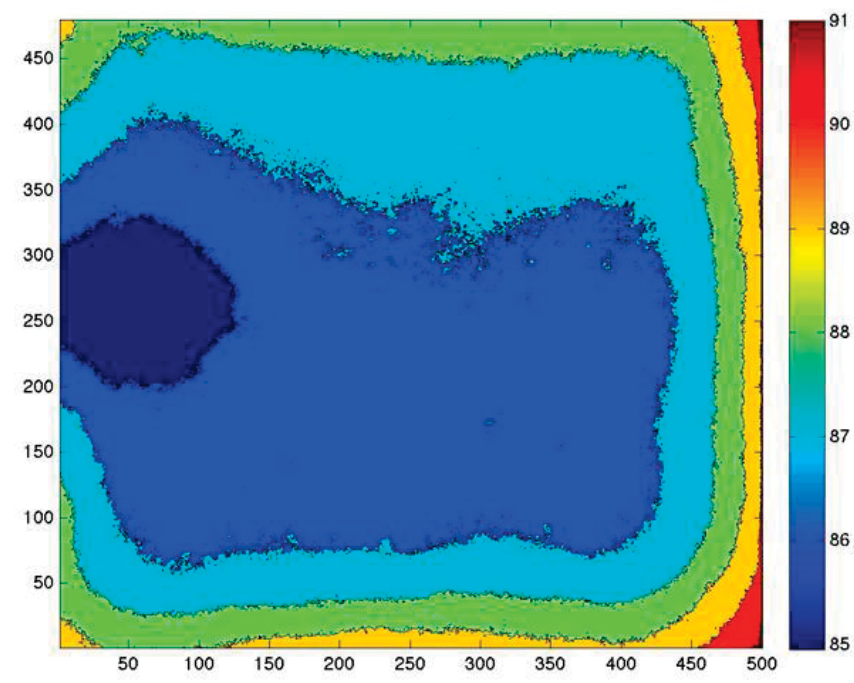

(b)

Figure 8. Contour plots of thermal loading in the slab without holes, at 20 minutes. (a) Line contours and (b) filled contours.

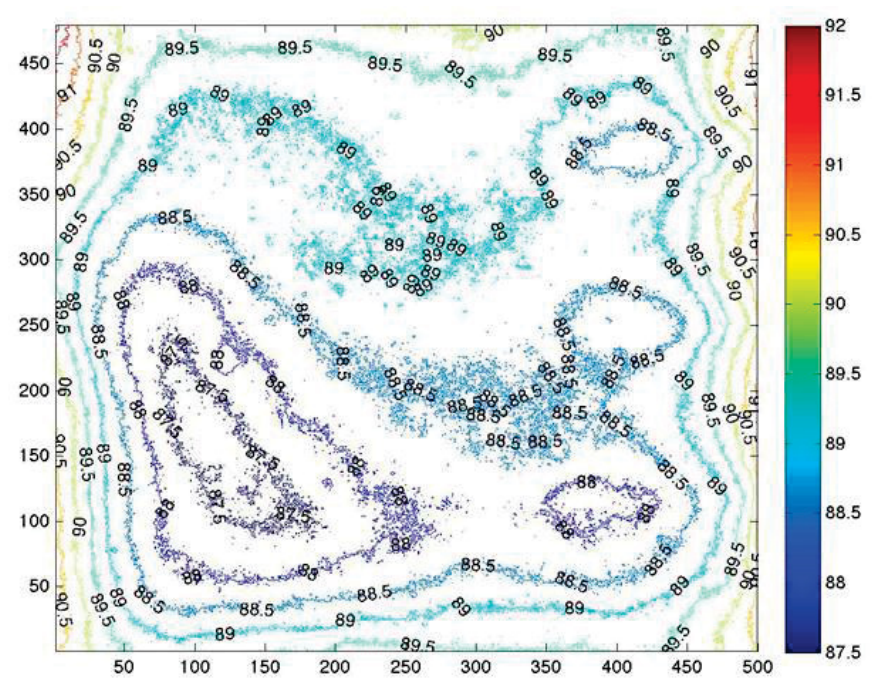

(a)

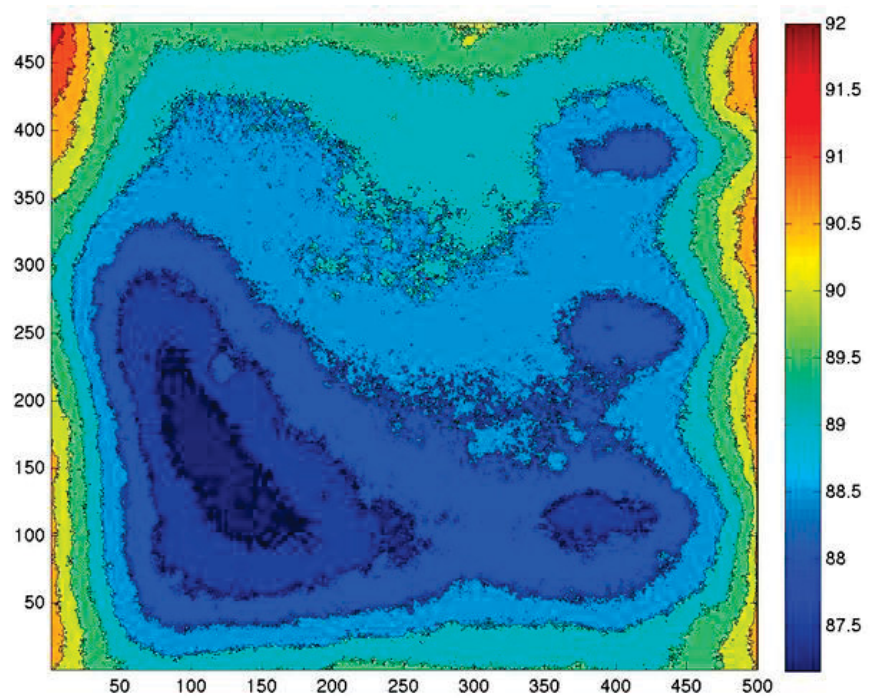

(b)

Figure 9. Contour plots of thermal loading in the slab with holes, at 20 minutes. (a) Line contours and (b) filled contours.

\subsection{Feature Extraction}

From the contour images shown in Figures 8 and 9, differences are seen between the contours of the slab without and with holes. However, a simple baseline removal method or simple gradient method is not effective enough to provide feature classification capability. Texture detection provided an additional opportunity to improve the classification of features in the image. Instead of simply classifying features by the temperature contour value or temperature value, the distribution of the colors is used because it is easier for visual classification of damage. The feature developed here is gradient based with baseline data subtracted from the observed data.

The gradient of an image is given by the formula:

$\nabla f=\frac{\partial f}{\partial x} \hat{x}+\frac{\partial f}{\partial y} \hat{y}$ 
where

$\frac{\partial f}{\partial x}$ is the gradient in the $\mathrm{x}$-direction and

$\frac{\partial f}{\partial y}$ is the gradient in y-direction.

The gradient direction can be calculated as:

$\theta=\arctan 2\left(\frac{\partial f}{\partial x}, \frac{\partial f}{\partial y}\right)$

To calculate the feature, the gradient along the $\mathrm{x}$ and y-directions of the images was calculated for the observed cases with baseline data subtracted. To describe the specific contour texture in the image, a characteristic value (or threshold value) was defined. In this study, after a few trials, based on the distributions of gradients along $\mathrm{x}$-axis and $\mathrm{y}$-axis, a threshold value of 0.1 was set. The specific texture is defined when:

$\frac{\partial f}{\partial x}$ is less than the threshold value and

$\frac{\partial f}{\partial y}$ is greater than the threshold value.

The images in Figure 10 are the classification results based on the features extracted by applying the gradient method to the images for the slab with holes.

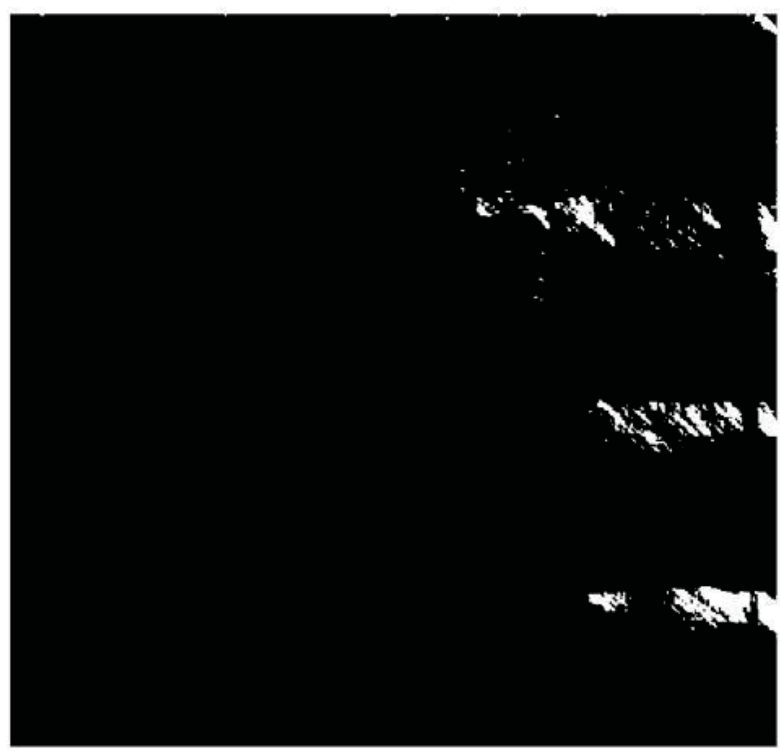

Figure 10. Feature extracted for the slab with holes.
This paper presented a probabilistic framework for concrete structures health monitoring in NPPs. Monitoring and data analytic elements of the framework in particular were discussed in detail in this paper. Full-field imaging techniques were discussed and applied on a concrete slab with holes (i.e., holes were representative of damage). The data collected using full-field imaging techniques were processed and analyzed to diagnose damages using contour mapping techniques. Based on contour mapping, a gradient-based feature extraction technique was applied to extract features.

In the longer term, this research will investigate monitoring of chemical-mechanical coupled degradation in concrete via full-field imaging techniques (thermal, optical, and vibratory) and acoustic measurements. Dynamic operating conditions (cycle loading, pressure variations, humidity, etc.) may lead to coupled chemical-mechanical degradation such as alkali-silica, reaction, fracture, corrosion, and internal swelling. The forward analysis of the evolution of concrete degradation is a challenging task in itself, which requires the combination of reactive transport modeling with mechanical degradation models.

\section{DISCLAIMER}

This information was prepared as an account of work sponsored by an agency of the U.S. Government. Neither the U.S. Government nor any agency thereof, nor any of their employees, makes any warranty, expressed or implied, or assumes any legal liability or responsibility for the accuracy, completeness, or usefulness, of any information, apparatus, product, or process disclosed, or represents that its use would not infringe privately owned rights. References herein to any specific commercial product, process, or service by trade name, trade mark, manufacturer, or otherwise, does not necessarily constitute or imply its endorsement, recommendation, or favoring by the U.S. Government or any agency thereof. The views and opinions of authors expressed herein do not necessarily state or reflect those of the U.S. Government or any agency thereof.

\section{REFERENCES}

Agarwal, V. \& Mahadevan, S. 2014. Concrete Structural Health Monitoring in Nuclear Power Plants. Office of Nuclear Energy Sensors and Instrumentation Newsletter, September 2014.

Bruck, P., Esselman, T., and Fallin, M. 2012. Digital Image Correlation for Nuclear. Nuclear Engineering International, April 23, 2012. 
Clayton, D. 2014. Nondestructive Evaluation Techniques for Nuclear Power Plant Concrete Structures. Light Water Reactor Sustainability (LWRS) Newsletter, Issue 14, U.S. Department of Energy, 2014.

Kobayashi, K. and Banthia, N. 2011. Corrosion detection in reinforced concrete using induction heating and infrared thermography. Journal of Civil Structural Health Monitoring, 1(2), pp. 25-35.

Mahadevan, S., Agarwal, V., Neal, K., Kossom, D., and Adams, D. 2014, Interim Report on Concrete Degradation Mechanisms and Online Monitoring Techniques, INL/EXT14 33134, Idaho National Laboratory, September 2014.

Naus, D. 2007. Activities in Support of Continuing the Service of Nuclear Power Plant Safety Related Concrete Structures. In Infrastructure Systems for Nuclear Energy (eds T. T. C. Hsu, C. L. Wu and J. L. Li), Chichester, UK: John Wiley \& Sons, Ltd.

Petrou, C. and Petrou, M. 2010. Image Processing: The fundamentals. 2nd edition, Wiley, John \& Sons, Incorporated.

\section{ACKNOWLEDGEMENT}

This report was made possible through funding by the U.S. Department of Energy (DOE) Light Water Reactor Sustainability (LWRS) Program. We are grateful to Richard Reister of DOE and Kathryn McCarthy at Idaho National Laboratory (INL) for championing this effort. 